\title{
Experimental investigation of the process of hydrate-formation by the method of explosive boiling of liquefied freon $134 a$ in the water volume during decompression
}

\author{
Anton V. Meleshkin ${ }^{1,}$, and Dmitriy S. Elistratov ${ }^{1}$ \\ ${ }^{1}$ Kutateladze Institute of Thermophysics, 630090 Novosibirsk, Russia
}

\begin{abstract}
The experiments on obtaining gas hydrate of refrigerant $134 \mathrm{a}$ were carried out by the method, based on explosive boiling-up of a layer of liquefied gas in a bulk of water at decompression. It is shown that this method combines several factors, leading to intensification of hydrate formation process, resulting in the fast gas hydrate growth. The effect of the decompression rate on the volume of produced hydrate was studied experimentally.
\end{abstract}

\section{Introduction}

As far back as in the beginning of the 20th century, the technological offers on the storage and transport of natural gas in the hydrate state appeared. This method attracts the experts attention for quite long time due to the property of gas hydrates to concentrate large volumes of gas at relatively low pressures. Without a pipeline a promising way of gas transportation is its conversion into the gas hydrate (solid) state and its transportation at the atmospheric pressure and low temperature $\left(\begin{array}{llll}-10 & \ldots & -20^{\circ} \mathrm{C}\end{array}\right)$ [1]. In [2-4] and some other paper, the properties of gas hydrates, basic conditions and features of their formation are described; the types of their crystallization, mechanisms of gas hydrate formation and decomposition are presented [5-11].

A shock-wave method for obtaining gas hydrates was proposed, the intensification of the hydrate formation process resulted from the imposition of several factors, such as an increase in the contact surface of the hydrate-forming gas-water due to the shattering of the bubbles by the shock wave, the transfer of the system far into the region of hydrate formation, and the acceleration of the bubbles with respect to water [12-13]. We continue to search for effective ways to intensify hydrate formation with the help of mechanical and thermal effects on gas-liquid media [14-17].

\footnotetext{
Corresponding author: mav@itp.nsc.ru
} 


\section{Experimental setup and methods}

The studies were carried out using the setup in the form of a high-pressure reactor of up to $25 \mathrm{MPa}$. The working section was made as a stainless steel vessel (diameter of $100 \mathrm{~mm}$, height of $300 \mathrm{~mm}$ ) with a water jacket for thermal stating (Fig.1).

The experiment has been performed in the following manner. Water in the amount of $200 \mathrm{ml}$ was into the reaction vessel and cooled by the cryostat through the outer walls to the temperature of hydrate formation. Further, $200 \mathrm{~g}$ of Freon 134a from the tank was fed into the water-filled vessel (with the temperature of $2-8^{\circ} \mathrm{C}$ ). The pressure in the tank is much higher than the pressure in the autoclave, and the temperature of gas in the tank is higher than the water temperature. Entering the autoclave, gas started pressurization. Gas was cooled to the temperature of water, causing it liquation and accumulation in the form of a layer on the autoclave bottom. Then the pressure was decreased, liquefied gas under the water layer started boiling over the entire volume, so that there was an increase in interfacial surface. On the bubble walls, the growth of the gas hydrate layer started. Due to active boiling, the bubbles with the hydrate film, formed on the interface, collided constantly and deformed, causing the hydrate film peeling, and the rate of hydrate formation did not decreased. The heat released during hydrate formation was compensated by heat absorption during boiling. Due to superposition of these processes, there was a fast increase in the mass of gas hydrate.

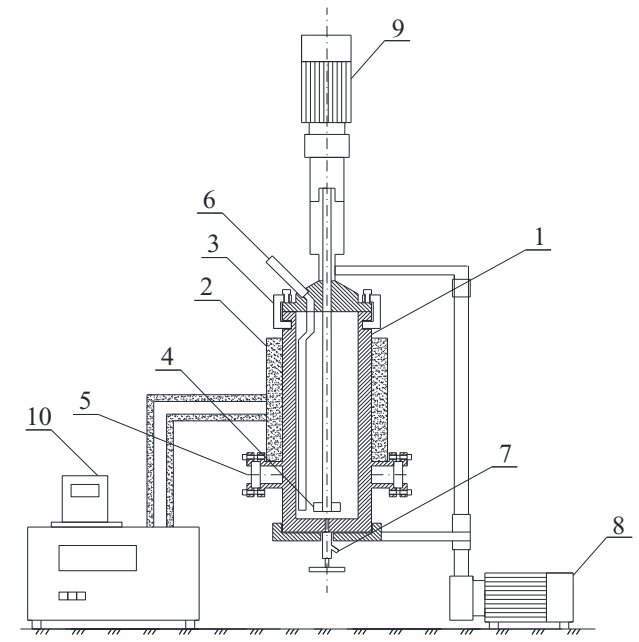

Fig. 1. Scheme of experimental setup: 1 - vessel; 2 - water jacket; 3 - lid; 4 - mixer; 5 - viewing windows; 6 - bottom tube; 7 - bottom valve; 8 - drive for working section lowering/lifting; 9 - mixer drive; 10 - cryostat.

In the course of experimental studies, gas-hydrates of Freon R134a, carbon dioxide and propane were obtained. In Fig. 2,3 shows the dependence of pressure and average temperature on the working site on time, when obtaining Freon gas hydrate 134a. The ideal formula for the unit cell of freon gas hydrate $134 \mathrm{a}$ is known to be $8 \mathrm{CH} 2 \mathrm{FCF} 3 * 136 \mathrm{H} 2 \mathrm{O}$, the crystal structure of hydrate II. Thus, the mass fraction of gas $\mathrm{k}$ in pure hydrate is $25 \%$. As can be seen in Fig. 3, as a consequence of the decompression, a rapid pressure drop occurred in the system, which led to an explosive boiling of the liquefied gas. Intensive boiling resulted in a slight increase in pressure, after which the boiling intensity decreased and the pressure dropped to the ambient pressure. In addition, the average temperature decreased (due to phase transition and external cooling) and reached minus levels. 
In Fig. 4 shows the same process on the P-T diagram. The process begins at a place where the coolant passes into the region where it exists in a gas-different state. It is worth noting that formation of gas hydrate is possible in both regions. But the process of explosive boiling initiated by decompression significantly improves the formation of the gas hydrate (the rate of hydrate formation increases by several orders of magnitude).

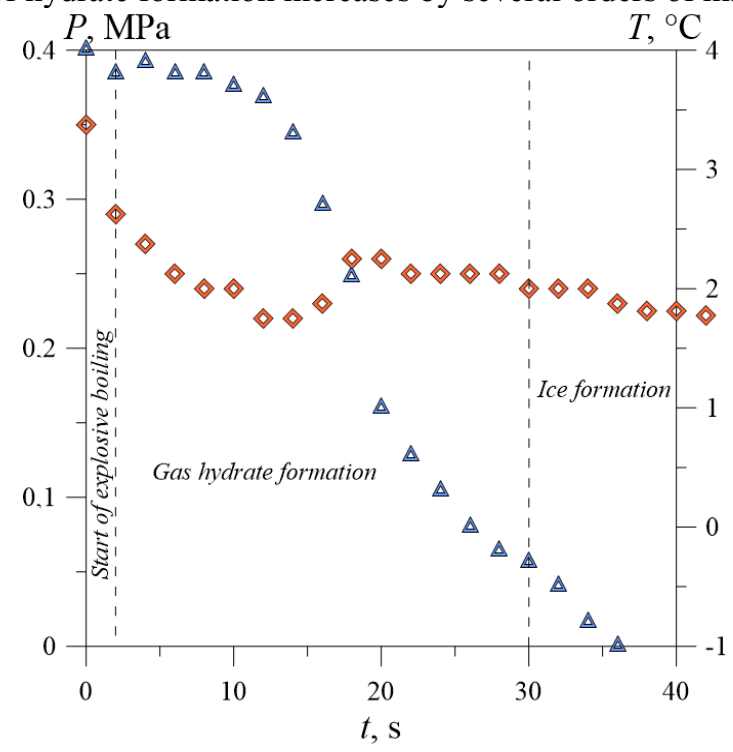

Fig. 2. Dependence of pressure $P$ (rhombus) and average temperature (triangles) on the working site on time.

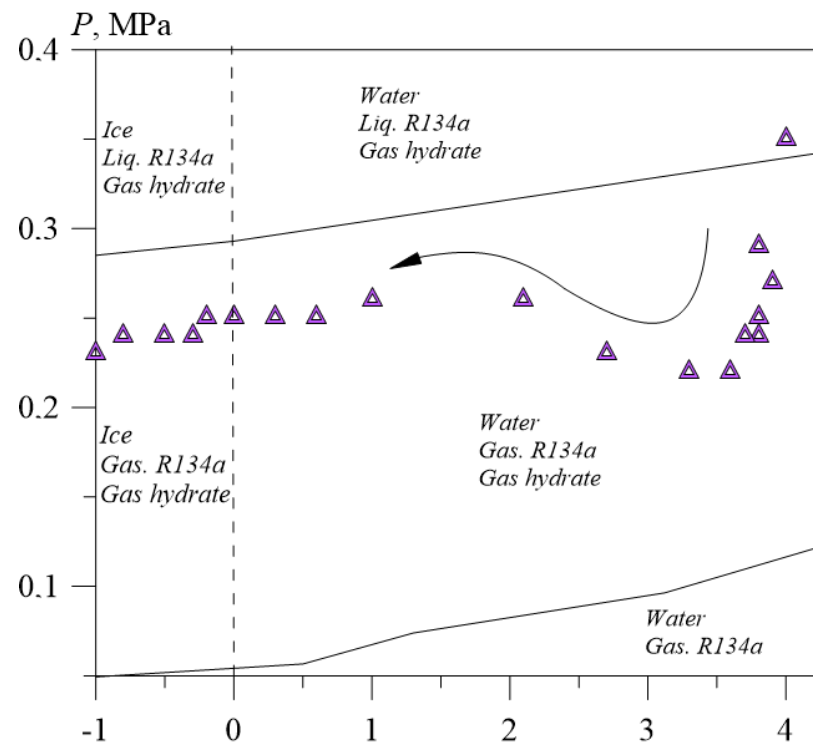

Fig. 3. P-T diagram of the process (triangles); the upper solid line is the Freon 134a boiling curve; the lower solid line is the equilibrium line of freon gas hydrate $134 \mathrm{a}$.

The decomposition of the obtained sample showed that the initial mass concentration of the gas was about $20 \%$. Thus, about $70 \%$ of the sample obtained in the experiment is a gas hydrate. 


\section{Conclusion}

In this work, a new method of obtaining gas hydrates based on the boiling of liquefied gas under the surface of water as a result of decompression was experimentally investigated. The process of obtaining Freon 134a gas hydrate has been described, the advantages of this method over others have been revealed. The study of decomposition of the obtained gas hydrate samples showed that the gas mass in it was about $20 \%$, which implies that the sample was $70 \%$ gas hydrate.

The study was funded by FASO Russia.

\section{References}

1. J. Gudmundsson, M. Mork, O. Graff, Proc. Of the 4th Intern. Conf. on gas hydrates (2002)

2. Y. F. Makogon, Hydrates of Hydrocarbons (PennWell Books, Tulsa, 1997)

3. V. S. Yakushev, V. A. Istomin, Physics and Chemistry of Ice (Hokkaido University Press, Hokkaido, 1993)

4. E. D. Sloan, C. A. Koh, 3rd ed Chemical industries series 721 (2008)

5. V. Sh. Shagapov, N. G. Musakaev, M. K. Khasanov, Int. J. Heat Mass Transfer 84, 1030 (2015)

6. V. Sh. Shagapov, M. K. Khasanov, N. G. Musakaev, Int. J. Heat Mass Transfer 107, 347 (2017)

7. N. G. Musakaev, M. K. Khasanov, S. L. Borodin, Int. J. Heat Mass Transfer 118, 455 (2018)

8. M. Z. Faizullin, A. V. Vinogradov, V. P. Koverda, Chem. Eng. Sci. 130, 135 (2015)

9. S. Y. Misyura, Sci. Rep. 6, 30324 (2016)

10. V. E. Nakoryakov, S. Y. Misura, S. L. Elistratov, A. Yu. Manakov, A. A. Sizikov, J. Eng.Thermophys. 22, 169 (2013)

11. V. E. Nakoryakov, S. Y. Misura, S. L. J. Eng. Thermophys. 25, 24 (2016)

12. V. E. Dontsov, A. A. Chernov Int. J. Heat Mass Transfer 52, 4919 (2009)

13. A. A. Chernov, V. E. Dontsov, Int. J. Heat Mass Transfer 54, 4307 (2011)

14. A. A. Chernov, A. A. Pil'nik, D. S. Elistratov, I. V. Mezentsev, A. V. Meleshkin, M. V. Bartashevich, M. G. Vlasenko, Sci. Rep. 7, 40809 (2017)

15. A. A. Chernov, D. S. Elistratov, I. V. Mezentsev, A. V. Meleshkin, A. A. Pil'nik, Int. J. Heat Mass Transfer 108, 1320 (2017)

16. V. E. Nakoryakov, A. N. Tsoi, I. V. Mezentsev, A. V. Meleshkin, J. Eng. Thermophys. 23, 1 (2014)

17. V. E. Nakoryakov, A. N. Tsoi, I. V. Mezentsev, A. V. Meleshkin, T and A 21, 279 (2014) 